\title{
Effect of short-term lycopene supplementation and postprandial dyslipidemia on plasma antioxidants and biomarkers of endothelial health in young, healthy individuals
}

\author{
Steven G Denniss \\ Thomas D Haffner \\ Jeffrey $T$ Kroetsch \\ Sara R Davidson \\ James WE Rush \\ Richard L Hughson
}

Faculty of Applied Health Sciences, University of Waterloo, Waterloo,

ON, Canada N2L 3G I
Correspondence: Richard L Hughson Faculty of Applied Health Sciences, University of Waterloo, 200 University Ave.W.,Waterloo, Ontario, Canada N2L $3 \mathrm{GI}$

Tel + I 5198884567 ext 32516

Fax +I 5197466776

Email hughson@uwaterloo.ca

\begin{abstract}
The objective of this study was to test the hypothesis that the effect of a high-fat meal (HFm) on plasma lipid-soluble antioxidants and biomarkers of vascular oxidative stress and inflammation would be attenuated by short-term lycopene supplementation in young healthy subjects. Following restriction of lycopene-containing foods for 1-wk (LYr), blood was collected in a fasting state and $3 \mathrm{~h}$ after a HFm and a low-fat meal (LFm) in $\mathrm{N}=18$ men aged $23 \pm 2$ years, and after a HFm only in $\mathrm{N}=9$ women aged $23 \pm 1$ years. Blood was also sampled pre- and post-meals following 1-wk of $80 \mathrm{mg}$ /day lycopene supplementation (LYs) under continued dietary LYr. In the fasting state, LYs compared with LYr not only evoked a $>2$-fold increase in plasma lycopene but also increased plasma $\beta$-carotene and $\alpha$-tocopherol $(p<0.01)$, though LYs did not affect plasma nitrate/nitrite (biomarker of nitric oxide), malondialdehyde (biomarker of lipid oxidative stress), vascular- and intercellular-adhesion molecules or C-reactive protein (biomarkers of inflammation). Contrary to the hypothesis, the HFm-induced dyslipidemic state did not affect plasma malondialdehyde, C-reactive protein, or adhesion molecules in either LYr or LYs. Both the HFm and LFm were associated with decreases in the nitric oxide metabolites nitrate/nitrite and lipid-soluble antioxidants $(\mathrm{p}<0.05)$. The data revealed that 1 -wk of LYs increased plasma lycopene, $\beta$-carotene, and $\alpha$-tocopherol yet despite these marked changes to the plasma lipid-soluble antioxidant pool, biomarkers of vascular oxidative stress and inflammation were unaffected in the fasted state as well as during dyslipidemia induced by a HFm in young healthy subjects.
\end{abstract}

Keywords: carotenoids, dietary antioxidants, high-fat meal, low-fat meal

\section{Introduction}

Lycopene is a highly unsaturated acyclic carotenoid found predominantly in tomato products (Clinton 1998). This lipophilic compound is transported in the blood by lipoproteins and accumulates in many human tissues including the vasculature (Suarna et al 1995; Stahl and Sies 1996). Recent epidemiological studies have strongly associated lycopene with reduced carotid intima-media thickness and lower incidences of myocardial infarction, ischemic heart disease, and stroke (Kohlmeier et al 1997; Gianetti et al 2002; Rissanen et al 2002, 2003). Accordingly, laboratory experiments have begun to investigate the role of lycopene on the health of the cardiovascular system.

Lycopene is a potent chemical antioxidant shown to quench reactive oxygen species in vitro (Bohm et al 1995) and to decrease blood lipid biomarkers of oxidative stress in vivo (Agarwal and Rao 1998; Rao and Agarwal 1998). Cell culture experiments have established that lycopene can inhibit the destruction of nitric oxide by superoxide anion (Panasenko et al 2000) and attenuate inflammatory cytokine-stimulated endothelial cell adhesion molecule expression and monocyte-endothelial interactions (Martin et al 
2000). Moreover, a study in mice reported that lyophilized tomato lycopene supplementation protected against endothelial vasomotor dysfunction developed in response to a 4 month atherogenic high-fat diet (Suganuma and Inakuma 1999). Interestingly, even in the first hours after a single high-fat meal consumed by middle-aged healthy, nondiabetic humans aged 35-55 years a transient dyslipidemia has been associated with an increase in blood lipid biomarkers of oxidative stress and inflammation (Anderson et al 2001; Bae et al 2001; Ceriello et al 2002, 2004; Nappo et al 2002) and a decrease in endothelial nitric oxide-mediated vasomotor function (Vogel et al 1997; Anderson et al 2001; Bae et al 2001; Ceriello et al 2002), while these effects may be reversed with various antioxidant compounds (Nappo et al 2002; Carroll and Schade 2003; Esposito et al 2003; Plotnick et al 2003). In comparison, studies investigating postprandial effects in younger healthy subjects aged 20-35 years have found that high-fat meal-induced transient dyslipidemia may result in impaired endothelial vasomotor function either with (van Oostrom et al 2003; Tsai et al 2004) or without (Schinkovitz et al 2001; Bae et al 2003) an associated increase in oxidative stress and/or inflammatory markers. Because vascular cell phenotype/function (Widlansky et al 2003), oxidative stress and inflammation (Hansson 2001; Stocker and Keaney Jr. 2004), and the postprandial state (de Koning and Rabelink 2002) have emerged as important considerations for understanding the physiopathology of early cardiovascular dysfunction in time leading to disease, further investigation into the role of lycopene supplementation might reveal a mechanistic basis for the epidemiological association between lycopene and cardiovascular protection.

The purpose of the present study was to determine the effect of short-term lycopene supplementation and postprandial dyslipidemia induced by a single 'fast food' high-fat meal on plasma lipid-soluble antioxidants and biomarkers of vascular oxidative stress and inflammation in healthy young subjects not yet complicated by cardiovascular dysfunction or overt disease. It was hypothesized that by requesting our subjects to eliminate lycopene-containing foods for 1-wk then providing them with a pure lycopene extract for 1-wk while maintaining the restriction on lycopene-containing foods we might be able to elevate plasma lycopene in isolation, and that this would be associated with an increase in plasma biomarkers of endothelial nitric oxide production and a decrease in vascular oxidative stress and inflammation. Furthermore, it was hypothesized that ingesting a high-fat meal (HFm) following lycopene-containing food restriction would decrease plasma biomarkers of endothelial nitric oxide production and increase vascular oxidative stress and inflammation, and that these effects would be mitigated by antioxidant lycopene supplementation.

\section{Materials and methods Subjects}

Eighteen healthy men aged 23 (SD 2) years (range, 18-26 years) and nine healthy women aged 23 (SD 1) years (range, 21-24 years) with a body mass index between $20-30 \mathrm{~kg} / \mathrm{m}^{2}$ volunteered for this study. Entry criteria specified during recruitment, which was done by displaying subject recruitment flyers about the university campus, included nontobacco users with no family history of premature cardiovascular disease and an absence of diagnosed hypertension, dyslipidemia, and diabetes mellitus. At the time of the first set of experiments, four of the women were in the early luteal phase (day 17-20), four were in the late luteal phase (day 26-28), and one was in the early follicular phase (day 5; menses) of the ovarian cycle. All subjects were regularly physically active but untrained, performing at least 1 -h of aerobic exercise most days of the week, and self-reported having a relatively healthy, balanced diet that was low in (but not exclusive of) fast-food intake. They took no medications, including multivitamin/antioxidant supplements, for at least one month prior to the study, and they abstained from alcohol, caffeine, and formal exercise for at least 24-h before each laboratory session. The study was approved by the Office of Research Ethics at the University of Waterloo and subjects gave informed written consent.

\section{Study design}

One week prior to the commencement of the first set of experiments, subjects were familiarized with the study design and habitual fasting blood samples were collected from the antecubital vein by venipuncture into vacutainer tubes containing either heparin, EDTA, or no anticoagulant (Becton Dickinson, Franklin Lakes, NJ, USA). Subjects were instructed on which foods contained lycopene and told to avoid these foods, and any dishes containing these foods, throughout the entire duration of the study while otherwise maintaining their habitual diet as best they could. The list of food items to be avoided (including juices, sauces, soups, mixed dishes etc) included apricots, grapefruit, guava, papaya, tomato, and watermelon. Subjects returned to the laboratory after dietary restriction of lycopene-containing foods for 1-wk (LYr) for the first phase of testing. In the men, blood samples were collected in the fasting state and then again 3-h after ingesting either a 'fast food' high-fat 
meal (HFm) or an isocaloric low-fat meal (LFm). The time point of 3-h for blood sampling following ingestion of the meals was chosen based on previous studies demonstrating that plasma dyslipidemia, biomarkers of vascular oxidative stress and inflammation, and endothelial cell dysfunction in healthy subjects increased to a peak at 2-4 hours after ingestion of a HFm (Marchesi et al 2000; Ceriello et al 2002, 2004; Tsai et al 2004). The HFm and the LFm were provided on two consecutive days with the order counterbalanced so that 9 men received the HFm on the first day and the LFm on the second day and vice versa for the other 9 men. The HFm (49\% total fat) consisted of an Egg McMuffin ${ }^{\circledR}$, a Sausage McMuffin $^{\circledR}$, two hash brown patties, and $250 \mathrm{ml}$ of $2 \%$ milk (1107 kcal total energy containing $100 \mathrm{~g}$ carbohydrates, $44 \mathrm{~g}$ protein, $60 \mathrm{~g}$ fat including $24 \mathrm{~g}$ saturated fat and $4 \mathrm{~g}$ trans fat, and 308 mg cholesterol; McDonald's Corporation, Canada). This HFm was commercially prepared and selected because it contained the same foods shown previously in middle-aged subjects to cause dyslipidemia and impaired endothelial function that was reversed by antioxidant supplementation (Vogel et al 1997; Plotnick et al 2003); however, it is impossible to state that the meal content was identical since there might be differences in suppliers of meal components and food preparation that could cause different responses (Vogel et al 1997; Williams et al 1999). The LFm (2\% total fat) consisted of $200 \mathrm{~g}$ of frosted flakes cereal, $580 \mathrm{ml}$ of skimmed milk, and $460 \mathrm{ml}$ of a flavored sugar drink $(1110 \mathrm{kcal}$ total energy containing $243 \mathrm{~g}$ carbohydrates, $28 \mathrm{~g}$ protein, $2 \mathrm{~g}$ fat, and $0 \mathrm{mg}$ cholesterol). For the female subjects, only the HFm was studied. Our female subjects were recruited into the study after we studied the men and compared their blood biochemical responses to the HFm and the LFm (see Blood processing and biochemical analyses, Methods below), and since the HFm did not provoke responses in blood antioxidants or biomarkers of endothelial health that differed substantially from the LFm responses (see Results), the focus of investigation in the females was narrowed to the HFm postprandial state and to a select range of biochemical responses. Blood samples were collected from the women in the fasting state and then again 3-h after ingesting a similar 'fast food' HFm that was slightly lower in total energy content in an attempt to account for differences in average daily caloric intake between men and women. This HFm (48\% total fat) consisted of an Egg McMuffin $^{\circledR}$, a Sausage McMuffin ${ }^{\circledR}$, one hash brown patty, and $250 \mathrm{ml}$ of $2 \%$ milk (957 kcal total energy containing $84 \mathrm{~g}$ carbohydrates, $42 \mathrm{~g}$ protein, $51 \mathrm{~g}$ fat including $20 \mathrm{~g}$ saturated fat and $3 \mathrm{~g}$ trans fat, and $303 \mathrm{mg}$ cholesterol; McDonald's Corporation, Canada). During the 3 -h between when the meals were consumed and the post-meal blood sampling, subjects were allowed to leave the laboratory unsupervised with the request to remain as sedentary as possible and not to eat. Following an additional 1-wk during which subjects continued to restrict lycopene from their diet but took a $80 \mathrm{mg}$ /day lycopene extract supplement (LYs $-4 \times 10 \mathrm{mg}$ capsules taken with food in the morning and the evening; Lyc-O-Mato, Herbal Select Company, Guelph, Canada), additional blood samples were collected 12-h following the last dose of lycopene in a fasting state and 3-h after ingestion of the same meals outlined above. An $80 \mathrm{mg}$ daily dosage of lycopene extract was chosen based on previous studies demonstrating that supplementation with $96.5 \%$ pure lycopene tomato oleoresin (equivalent to $75 \mathrm{mg}$ /day of lycopene) daily for 1-wk following LYr resulted in a $>2$-fold increase in serum lycopene concentration and an $\sim 20 \%-25 \%$ decrease in serum lipid biomarkers of oxidative stress (Agarwal and Rao 1998; Rao and Agarwal 1998). Subjects recorded all food and drink consumed daily in diet logs throughout the entire study.

\section{Blood processing and biochemical analyses}

Within 30-min of each venipuncture sampling, blood was centrifuged and the resultant serum and plasma supernatants were transferred to labeled microtubes and frozen at $-80^{\circ} \mathrm{C}$. All quantification of processed blood described below was performed within 6- to 8-wks of blood sampling. Blood lycopene, $\beta$-carotene, $\alpha$-tocopherol, retinol, cholesterol, triacylglycerol, glucose, insulin, and nitrate/nitrite-derived NO·concentrations were determined from all men and women across all conditions. Employing a HPLC procedure developed by Su and colleagues (1999) (Waters, Milford MA, Model 2695 solvent delivery pump and autosampler, Model 2996 photodiode array detector, $250 \times 4.6 \mathrm{~mm}$ Spherisorb ODS2 reversed phase $\mathrm{C}_{18}$ column with $5 \mu \mathrm{m}$ particle diameter and $\mathrm{C}_{18} 10 \times 4.6 \mathrm{~mm}$ guard column), the lipid-soluble antioxidants lycopene (trans + cis), $\beta$-carotene, $\alpha$-tocopherol, and retinol were quantified in heparinized plasma samples (HPLC-grade solvents/reagents from Fisher Scientific, Whitby, Canada; $>95 \%$ pure standards from Sigma Chemicals, St. Louis MO). Total cholesterol, HDL cholesterol, and triacylglycerol were quantified in heparinized plasma using standard enzymatic reagent assay kits (Catalog No. 225-28, 200-26, and 210-75 respectively; Diagnostic Chemicals Ltd., Charlottetown, Canada) and a microplate spectrophotometer (SPECTRAmax PLUS 384, Sunnyvale CA). Serum glucose was quantified spectrophotometrically 
(UV-160U, Shimadzu Corp., Tokyo, Japan) according to standard enzymatic methods (Catalog No. 510-6, D-3252, and 635-100 from Sigma Chemicals, St. Louis MO), and a solid-phase Coat-a-Count ${ }^{\circledR 125}$ I radioimmunoassay kit (Catalog No. TKIN5 from Diagnostic Products Corp., Los Angeles CA) and gamma counter (Beckman Gamma 5500, Irvine CA) were used to quantify serum insulin. Plasma nitrate/nitrite, taken as a biomarker of total nitric oxide metabolites, was determined by a nitric oxide analyzer (Model 280i, Sievers Instruments, Inc., Boulder $\mathrm{CO}$ ) to quantify nitric oxide gas generated from the reaction between plasma nitrate/nitrite and heated vanadium (III) chloride (high purity sodium nitrate from BioShop Inc., Burlington, Canada; HPLC-grade ethanol from Fisher Chemicals, Fairlawn NJ; vanadium (III) chloride from Sigma-Aldrich, St. Louis MO). The blood lipid biomarker of oxidative stress malondialdehyde was determined in samples from the first 10 men studied across all conditions. Prior to quantification, malondialdehyde in EDTA plasma samples was hydrolyzed/derivatized and extracted according to methods adopted from Sim and colleagues (2003) and Rodriguez and colleagues (2003) respectively $(\mathrm{NaOH}$ from Fisher Scientific, Whitby, Canada; $70 \%$ perchloric acid from BDH, Toronto, Canada; 97\% pure 2,4-dinitrophenylhydrazine from Sigma Chemicals, St. Louis MO; Amberlite ${ }^{\circledR} \mathrm{XAD}^{\circledR}-2$ from Supelco, Bellefonte PA), using 95\% pure acid hydrolyzed 1,1,3,3tetraethoxypropane as the malondialdehyde standard and $>99 \%$ pure benzaldehyde as an internal standard (Sigma Chemicals, St. Louis MO). The derivatized malondialdehyde extract was then quantified by employing a HPLC procedure modified from Pilz et al (Pilz et al 2000) $(250 \times 4.6 \mathrm{~mm}$ Spherisorb ODS2 reversed phase $\mathrm{C}_{18}$ column with $5 \mu \mathrm{m}$ particle diameter and $\mathrm{C}_{18} 10 \times 4.6 \mathrm{~mm}$ guard column from Waters, Milford MA; HPLC-grade solvents/reagents from Fisher Scientific, Whitby, Canada). Soluble intercellular adhesion molecule-1 (sICAM-1) and vascular cell adhesion molecule-1 (sVCAM-1), and high-sensitivity C-reactive protein (CRP) are blood biomarkers of inflammation and have been shown to predict increased risk of future cardiovascular disease in apparently healthy individuals (Ridker et al 1998; Koenig et al 1999). From the blood of the remaining 8 men whose plasma malondialdehyde concentration was not determined, serum sICAM-1, sVCAM-1, and CRP were quantified following LYr and LYs both in a fasting state and 3-h after ingesting the HFm using standard enzyme-linked immunosorbent assay kits (sICAM-1 Catalog No. BBE 1B and sVCAM-1 Catalog No. BBE 3, R\&D Systems Inc., Minneapolis MN; CRP Catalog No. 2210, Life Diagnostics,
West Chester PA) and a microplate spectrophotometer (SPECTRAmax PLUS 384, Sunnyvale CA). This decision was made based on considering the limited quantity of blood that remained to be analyzed, the fact that plasma malondialdehyde was found to be unchanged across all conditions in the first 10 men studied (see Results), and the desire to also have blood biomarkers of inflammation following LYs and in the postprandial state, especially after the HFm where inflammatory biomarker changes are most probable.

\section{Statistical analyses}

All data are presented as means with standard deviations (SD). Statistical analyses were performed using the Statistical Analysis Software program (SAS Institute, Cary NC). The effects of lycopene manipulation (Habitual, LYr, LYs) and the HFm (fasting, 3-h post) on blood biochemical variables in men or in women were evaluated by two-way repeatedmeasures ANOVA. Similarly, the effects of lycopene manipulation and the LFm on blood biochemical variables in men were evaluated by two-way repeated-measures ANOVA. Comparisons of men vs women were tested for LYr and LYs on fasting biochemical variables by repeatedmeasures ANOVA. A probability of 0.05 was accepted as statistically significant, with any main effects and interactions in the above ANOVAs reaching this probability further evaluated by least squares difference post hoc testing.

\section{Results Effects of LYr and LYs on blood lipid-soluble antioxidants}

Habitual plasma lycopene [men: 0.93 (SD 0.25) $\mu \mathrm{mol} / \mathrm{L}$; women: 0.49 (SD 0.18) $\mu \mathrm{mol} / \mathrm{L}$; Figure 1A] and retinol [men: 3.57 (SD 0.68) $\mu \mathrm{mol} / \mathrm{L}$; women: 2.82 (SD 1.11) $\mu \mathrm{mol} / \mathrm{L}$; Figure 1D] were significantly lower in women compared with men $[\mathrm{p}<0.01$ and $\mathrm{p}=0.03$ respectively] whereas plasma $\beta$-carotene [men: 0.29 (SD 0.20) $\mu \mathrm{mol} / \mathrm{L}$; women: 0.34 (SD 0.24) $\mu \mathrm{mol} / \mathrm{L}$; Figure 1B] and $\alpha$-tocopherol [men: 16.61 (SD 5.13) $\mu \mathrm{mol} / \mathrm{L}$; women: 15.59 (SD 3.93) $\mu \mathrm{mol} / \mathrm{L}$; Figure 1C] were not statistically significantly different. One week of LYr decreased plasma lycopene by 39\%-48\% in both men and women compared with habitual diet [p $<0.01$ ], and a subsequent 1-wk of LYs increased plasma lycopene by $114 \%$ in men and by a smaller but still marked $88 \%$ in women [men and women both $\mathrm{p}<0.01$; Figure $1 \mathrm{~A}$ ]. Neither LYr nor LYs affected plasma retinol [Figure 1D]. Lycopene restriction did not affect plasma $\beta$-carotene in men 

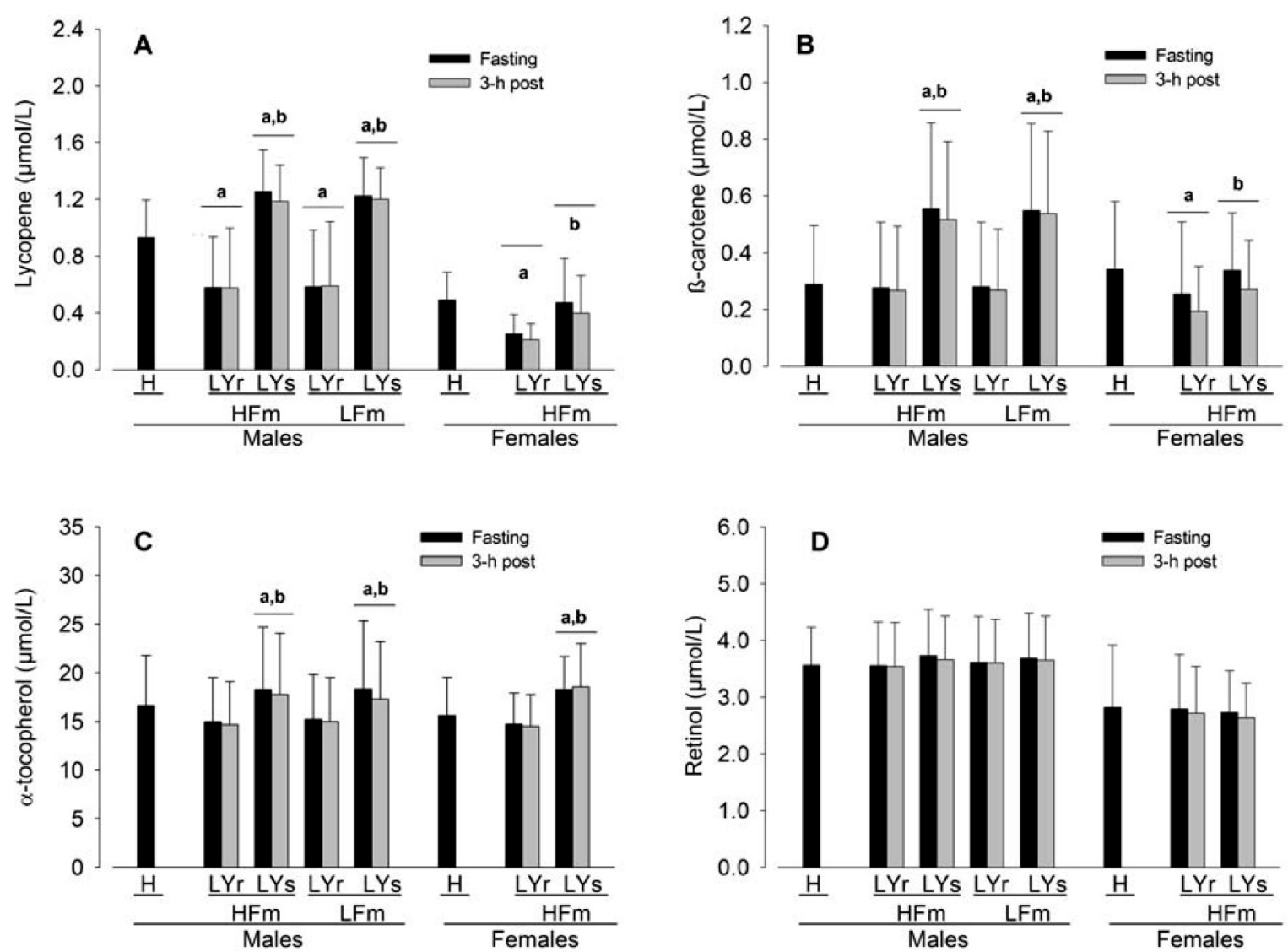

Figure I Plasma concentration of lycopene $(\mathbf{A}), \beta$-carotene $(\mathbf{B}), \alpha$-tocopherol $(\mathbf{C})$, and retinol $(\mathbf{D})$ in men $(n=18)$ and women $(n=9)$ after a habitual diet $(H)$ and after a I-wk lycopene-containing food restricted diet (LYr) followed by I-wk of supplementation with a $80 \mathrm{mg} /$ day $>98 \%$ pure lycopene (LYs) under continued LYr in both a fasting state and 3-h post high-fat meal (HFm) and low-fat meal (LFm) in men and 3-h post HFm in women.Values are means (SD). $\mathrm{P}<0.05$.

adenotes a significant effect of either the LYr or LYs condition compared to the $\mathrm{H}$ condition, and ${ }^{b}$ denotes a significant effect of the LYs condition compared to the LYr condition. There were no significant interactions. See Results for details of main effect sex and meal statistical comparisons.

compared to habitual food intake but was associated with a $31 \%$ decrease in women $[p=0.02$; Figure $1 B]$. In contrast, with LYr there was an $8 \%$ decrease in plasma $\alpha$-tocopherol in men [p $<0.01]$ but not in women compared with habitual food intake [Figure 1C]. Lycopene supplementation was associated with a $104 \%$ increase in plasma $\beta$-carotene in men and a smaller $(\mathrm{p}=0.03)$ but still significant $31 \%$ increase in women [Figure 1B], whereas plasma $\alpha$-tocopherol increased similarly in both men and women following LYs [men: $21 \%$; women: $24 \% ; \mathrm{p}<0.01$; Figure 1C]. HPLC analysis of the supplement verified a composition of $>98 \%$ lycopene with no trace of $\alpha$-tocopherol or $\beta$-carotene, and analysis of the diet logs using Diet Analysis Plus software [V5.1, Wadsworth Publishing Co., Salem OR] indicated no detectable difference in the intake of Vitamin A retinol equivalents or Vitamin $\mathrm{E} \alpha$-tocopherol equivalents, or other micro- and macronutrients, between LYr and LYs weeks of the study [data not shown].

Diet $\log$ analysis also indicated that the average diet consumed during the study consisted of a 52:18:30 carbohydrate-to-protein-to-fat ratio with total energy and macronutrient intake within $80 \%-120 \%$ of Dietary Reference Intake guidelines for their age and sex (ie, total energy, 89\%; carbohydrates, $81 \%$; protein, $119 \%$; total fat, $89 \%$; saturated fat, $86 \%$; cholesterol, $108 \%$ ) except dietary fiber (61\%), suggesting that our subjects ate a relatively healthy, balanced diet throughout the LYr and LYs experimental weeks when they were asked to maintain their general habitual diet but eliminate all lycopene-containing foods. We do not have data for the general habitual diets of our subjects; however, all subjects reported that they maintained the same dietary patterns with the exception of avoiding lycopene-containing foods during the test period.

\section{Effect of LYs on other blood biochemical characteristics}

Blood lipid, glucose, insulin, nitrate/nitrite, malondialdehyde, sICAM, sVCAM, and CRP concentrations are reported in Table 1. These measures were not different between LYr 
Table I Biochemical characteristics measured in blood in relation to lycopene manipulation and meals

\begin{tabular}{|c|c|c|c|c|c|c|c|}
\hline \multirow[t]{2}{*}{$\operatorname{MEN}(N=18)$} & \multirow[t]{2}{*}{$\mathbf{n}$} & \multicolumn{2}{|l|}{$\mathbf{L Y r}$} & \multicolumn{2}{|l|}{ LYs } & \multirow{2}{*}{$\begin{array}{l}\text { Meal effect } \\
\text { p value }\end{array}$} & \multirow{2}{*}{$\begin{array}{l}\text { LYs effect } \\
\text { p value }\end{array}$} \\
\hline & & Fasting & 3-h post & Fasting & 3-h post & & \\
\hline \multicolumn{8}{|l|}{ HIGH-FAT MEAL } \\
\hline $\begin{array}{l}\text { Total cholesterol, } \\
\mathrm{mmol} / /\end{array}$ & 18 & $\begin{array}{l}4.9 \\
\text { (SD I.7) }\end{array}$ & $\begin{array}{l}4.8 \\
\text { (SD I.7) }\end{array}$ & $\begin{array}{l}4.7 \\
\text { (SD I.7) }\end{array}$ & $\begin{array}{l}4.5 \\
\text { (SD I.7) }\end{array}$ & 0.37 & 0.12 \\
\hline $\begin{array}{l}\mathrm{HDL} \text { cholesterol } \\
\mathrm{mmol} / \mathrm{l}\end{array}$ & 18 & $\begin{array}{l}1.8 \\
\text { (SD 0.8) }\end{array}$ & $\begin{array}{l}1.5 \\
\text { (SD 0.4) }\end{array}$ & $\begin{array}{l}1.6 \\
\text { (SD 0.8) }\end{array}$ & $\begin{array}{l}1.5 \\
\text { (SD 0.8) }\end{array}$ & $<0.01$ & 0.1 \\
\hline $\begin{array}{l}\text { Triacylglycerol, } \\
\mathrm{mmol} / \mathrm{l}\end{array}$ & 18 & $\begin{array}{l}0.8 \\
(\mathrm{SD} 0.4)\end{array}$ & $\begin{array}{l}1.6 \\
\text { (SD 0.8) }\end{array}$ & $\begin{array}{l}1.0 \\
\text { (SD 0.8) }\end{array}$ & $\begin{array}{l}1.9 \\
\text { (SD I.2) }\end{array}$ & $<0.01$ & 0.16 \\
\hline Glucose, $\mathrm{mmol} / \mathrm{l}$ & 18 & $\begin{array}{l}5.2 \\
(S D 0.8)\end{array}$ & $\begin{array}{l}5.4 \\
\text { (SD 0.8) }\end{array}$ & $\begin{array}{l}5.3 \\
\text { (SD I.2) }\end{array}$ & $\begin{array}{l}5.3 \\
\text { (SD I.2) }\end{array}$ & 0.51 & 0.88 \\
\hline Insulin, $\rho \mathrm{mol} / \mathrm{I}$ & 18 & $\begin{array}{l}49 \\
\text { (SD I7) }\end{array}$ & $\begin{array}{l}108 \\
\text { (SD 59) }\end{array}$ & $\begin{array}{l}46 \\
\text { (SD I7) }\end{array}$ & $\begin{array}{l}95 \\
\text { (SD 55) }\end{array}$ & $<0.01$ & 0.29 \\
\hline Nitrate/nitrite, $\mu \mathrm{mol} / /$ & 18 & $\begin{array}{l}35 \\
\text { (SD I7) }\end{array}$ & $\begin{array}{l}31 \\
\text { (SD I3) }\end{array}$ & $\begin{array}{l}32 \\
\text { (SD I7) }\end{array}$ & $\begin{array}{l}29 \\
\text { (SD I7) }\end{array}$ & $<0.01$ & 0.29 \\
\hline $\begin{array}{l}\text { Malondialdehyde, } \\
\mu \mathrm{mol} / \mathrm{l}\end{array}$ & 10 & $\begin{array}{l}7.5 \\
\text { (SD 2.2) }\end{array}$ & $\begin{array}{l}7.8 \\
\text { (SD 2.8) }\end{array}$ & $\begin{array}{l}7.7 \\
\text { (SD 2.2) }\end{array}$ & $\begin{array}{l}7.8 \\
\text { (SD 2.2) }\end{array}$ & 0.62 & 0.81 \\
\hline sICAM-I, ng/ml & 8 & $\begin{array}{l}178 \\
(S D 40)\end{array}$ & $\begin{array}{l}181 \\
(S D 42)\end{array}$ & $\begin{array}{l}220 \\
\text { (SD 99) }\end{array}$ & $\begin{array}{l}168 \\
\text { (SD 5I) }\end{array}$ & 0.29 & 0.4 \\
\hline sVCAM-I, ng/ml & 8 & $\begin{array}{l}44 \text { I } \\
\text { (SD I24) }\end{array}$ & $\begin{array}{l}416 \\
\text { (SD I44) }\end{array}$ & $\begin{array}{l}413 \\
\text { (SD I33) }\end{array}$ & $\begin{array}{l}392 \\
(S D \mid 4 I)\end{array}$ & 0.11 & 0.57 \\
\hline CRP, mg/l & 8 & $\begin{array}{l}0.4 \mathrm{I} \\
\text { (SD 0.35) }\end{array}$ & $\begin{array}{l}0.61 \\
\text { (SD 0.80) }\end{array}$ & $\begin{array}{l}0.37 \\
\text { (SD 0.45) }\end{array}$ & $\begin{array}{l}0.46 \\
\text { (SD 0.69) }\end{array}$ & 0.25 & 0.68 \\
\hline \multicolumn{8}{|l|}{ LOW-FAT MEAL } \\
\hline $\begin{array}{l}\text { Total cholesterol, } \\
\mathrm{mmol} / / \mathrm{l}\end{array}$ & 18 & $\begin{array}{l}4.6 \\
\text { (SD I.7) }\end{array}$ & $\begin{array}{l}4.7 \\
\text { (SD I.3) }\end{array}$ & $\begin{array}{l}4.5 \\
\text { (SD I.3) }\end{array}$ & $\begin{array}{l}4.4 \\
\text { (SD I.3) }\end{array}$ & 0.96 & 0.25 \\
\hline $\begin{array}{l}\mathrm{HDL} \text { cholesterol } \\
\mathrm{mmol} / \mathrm{l}\end{array}$ & 18 & $\begin{array}{l}1.5 \\
\text { (SD 0.4) }\end{array}$ & $\begin{array}{l}1.5 \\
\text { (SD 0.4) }\end{array}$ & $\begin{array}{l}1.4 \\
\text { (SD 0.4) }\end{array}$ & $\begin{array}{l}1.3 \\
\text { (SD 0.4) }\end{array}$ & 0.31 & 0.1 \\
\hline $\begin{array}{l}\text { Triacylglycerol, } \\
\mathrm{mmol} / \mathrm{l}\end{array}$ & 18 & $\begin{array}{l}0.8 \\
\text { (SD 0.4) }\end{array}$ & $\begin{array}{l}0.9 \\
\text { (SD 0.4) }\end{array}$ & $\begin{array}{l}0.8 \\
(S D 0.4)\end{array}$ & $\begin{array}{l}0.9 \\
\text { (SD 0.4) }\end{array}$ & 0.27 & 0.78 \\
\hline Glucose, $\mathrm{mmol} / \mathrm{l}$ & 18 & $\begin{array}{l}5.1 \\
\text { (SD 0.8) }\end{array}$ & $\begin{array}{l}4.6 \\
(S D 0.8)\end{array}$ & $\begin{array}{l}5.2 \\
(S D 0.8)\end{array}$ & $\begin{array}{l}4.9 \\
\text { (SD I.3) }\end{array}$ & 0.01 & 0.2 \\
\hline Insulin, $\rho \mathrm{mol} / \mathrm{I}$ & 18 & $\begin{array}{l}47 \\
\text { (SD I7) }\end{array}$ & $\begin{array}{l}173 \\
\text { (SD 93) }\end{array}$ & $\begin{array}{l}48 \\
(S D 21)\end{array}$ & $\begin{array}{l}169 \\
\text { (SD 106) }\end{array}$ & $<0.01$ & 0.93 \\
\hline Nitrate/nitrite, $\mu \mathrm{mol} / /$ & 18 & $\begin{array}{l}37 \\
(S D 2 I)\end{array}$ & $\begin{array}{l}30 \\
(S D \mid 3)\end{array}$ & $\begin{array}{l}39 \\
\text { (SD 32) }\end{array}$ & $\begin{array}{l}31 \\
\text { (SD 25) }\end{array}$ & $<0.01$ & 0.8 \\
\hline $\begin{array}{l}\text { Malondialdehyde, } \\
\mu \mathrm{mol} / / \\
\text { WOMEN }(\mathrm{N}=9) \\
\text { HIGH-FAT MEAL }\end{array}$ & 10 & $\begin{array}{l}7.9 \\
\text { (SD 2.2) }\end{array}$ & $\begin{array}{l}7.1 \\
\text { (SD I.9) }\end{array}$ & $\begin{array}{l}8.5 \\
\text { (SD 2.5) }\end{array}$ & $\begin{array}{l}7.7 \\
\text { (SD I.9) }\end{array}$ & 0.11 & 0.1 \\
\hline $\begin{array}{l}\text { Total cholesterol, } \\
\mathrm{mmol} / \mathrm{l}\end{array}$ & 9 & $\begin{array}{l}4.6 \\
(S D 0.9)\end{array}$ & $\begin{array}{l}5.1 \\
\text { (SD 0.9) }\end{array}$ & $\begin{array}{l}4.9 \\
(S D 0.9)\end{array}$ & $\begin{array}{l}4.6 \\
(S D 0.9)\end{array}$ & 0.48 & 0.44 \\
\hline $\begin{array}{l}\mathrm{HDL} \text {, cholesterol } \\
\mathrm{mmol} / \mathrm{l}\end{array}$ & 9 & $\begin{array}{l}2.0 \\
(\mathrm{SD} 0.9)\end{array}$ & $\begin{array}{l}1.8 \\
(S D 0.6)\end{array}$ & $\begin{array}{l}2.0 \\
(\mathrm{SD} 0.9)\end{array}$ & $\begin{array}{l}1.8 \\
(S D 0.6)\end{array}$ & 0.07 & 0.89 \\
\hline $\begin{array}{l}\text { Triacylglycerol, } \\
\mathrm{mmol} / \mathrm{l}\end{array}$ & 9 & $\begin{array}{l}0.8 \\
(\mathrm{SD} 0.3)\end{array}$ & $\begin{array}{l}1.5 \\
\text { (SD 0.6) }\end{array}$ & $\begin{array}{l}0.8 \\
(S D 0.3)\end{array}$ & $\begin{array}{l}1.3 \\
\text { (SD 0.3) }\end{array}$ & $<0.01$ & 0.16 \\
\hline Glucose, $\mathrm{mmol} / \mathrm{l}$ & 9 & $\begin{array}{l}4.6 \\
(S D 0.3)\end{array}$ & $\begin{array}{l}4.6 \\
(S D 0.6)\end{array}$ & $\begin{array}{l}5.3 \\
(S D 0.6)\end{array}$ & $\begin{array}{l}5.3 \\
(S D 0.6)\end{array}$ & 0.95 & $<0.01$ \\
\hline Insulin, $\rho \mathrm{mol} / \mathrm{I}$ & 9 & $\begin{array}{l}77 \\
\text { (SD 60) }\end{array}$ & $\begin{array}{l}208 \\
\text { (SD II7) }\end{array}$ & $\begin{array}{l}57 \\
\text { (SD 36) }\end{array}$ & $\begin{array}{l}148 \\
\text { (SD 57) }\end{array}$ & $<0.01$ & 0.08 \\
\hline Nitrate/nitrite, $\mu \mathrm{mol} / /$ & 9 & $\begin{array}{l}43 \\
\text { (SD 27) }\end{array}$ & $\begin{array}{l}29 \\
(\mathrm{SD} \mid 2)\end{array}$ & $\begin{array}{l}38 \\
(S D \mid 5)\end{array}$ & $\begin{array}{l}29 \\
(\mathrm{SD} 9)\end{array}$ & $<0.01$ & 0.68 \\
\hline
\end{tabular}

Notes: Values [means (SD)] were measured after a I-wk lycopene-containing food restricted diet (LYr) followed by I-wk of supplementation with a 80 mg/day $>98 \%$ pure lycopene (LYs) under continued LYr in both a fasting state and 3-h post high-fat meal and low-fat meal in men and 3-h post high-fat meal in women. Probability values for the main effects of LYs and Meal are presented. There were no significant interactions.

Abbreviations: sICAM-I, soluble intercellular adhesion molecule-I; sVCAM-I, vascular cell adhesion molecule-I; CRP, high-sensitivity C-reactive protein. 
and LYs for the men, nor did they differ in women with the exception of glucose which was significantly higher following LYs.

\section{Effect of high-fat and low-fat meal on blood lipid-soluble antioxidants}

In men, the HFm was associated with a $3 \%-4 \%$ decrease in each of plasma lycopene, $\beta$-carotene, and $\alpha$-tocopherol (Figure 1, $\mathrm{p}=0.03$ ). After the LFm, plasma $\alpha$-tocopherol was decreased by $3 \%$ in men $(p=0.03)$ whereas plasma lycopene and $\beta$-carotene were unaffected. In women, the HFm was associated with a $17 \%-20 \%$ decrease in plasma lycopene and $\beta$-carotene $(\mathrm{p}=0.01)$, whereas plasma $\alpha$-tocopherol was unaffected. Plasma retinol in men and women was unaffected following the meals. There were no significant interactions between Meal and LYs on blood lipid-soluble antioxidants.

\section{Effect of high-fat and low-fat meals on other blood biochemical characteristics}

Plasma triacylglycerol was increased $107 \%$ in men and $88 \%$ in women following the HFm but was no different following the LFm in men (Table 1). Plasma HDL cholesterol although unchanged after the LFm was 9\% decreased subsequent to the HFm in men, and the decrease following the HFm in women nearly reached the criterion for significance. There was no effect of the HFm or LFm in men or the HFm in women on plasma total cholesterol. Similarly, plasma malondialdehyde following the LFm and plasma malondialdehyde and serum sICAM-1, sVCAM-1, CRP following the HFm were unaffected in men (Table 1). Serum insulin was $260 \%$ increased and serum glucose was decreased 7\% after the LFm in men, and in response to the HFm serum insulin was increased $115 \%$ whereas serum glucose was unchanged. In women, serum insulin was increased $165 \%$ and serum glucose was unchanged after the HFm. Plasma nitrate/nitrite was decreased $19 \%$ following the LFm in men and was decreased $10 \%$ in men and $25 \%$ in women following the HFm. There were no significant interactions between Meal and LYs on any of these other blood biochemical characteristics.

\section{Discussion}

In the current study, we set out to test the hypothesis that LYs would increase plasma lycopene and the resulting improvement in lipid-soluble antioxidant status would reduce oxidative stress and inflammatory biomarkers and attenuate the responses of these biomarkers to a HFm. Consistent with our hypothesis, we did find an elevation of plasma lycopene but this was accompanied by an unexpected increase in plasma $\beta$-carotene and $\alpha$-tocopherol while there were no changes in fasting blood biomarkers of oxidative stress and inflammation. Another important finding of the current research was that the vascular system of young healthy men and women appeared to be capable of coping with the dyslipidemic state induced by the HFm even during the phase of LYr as well as following LYs so that biomarkers of oxidative stress and inflammation were unaffected. This observation was in contrast to our hypothesis and to a number of, but not all (Schinkovitz et al 2001; Bae et al 2003), previous studies in subjects both young (van Oostrom et al 2003; Tsai et al 2004; Tushuizen et al 2006) and middle-aged (Anderson et al 2001; Bae et al 2001; Nappo et al 2002; Ceriello et al 2002, 2004) upon which the hypothesis was based.

\section{Plasma lipid-soluble antioxidants, metabolites, and biomarkers}

The LYr phase in the present study caused plasma lycopene to be reduced by approximately one-half suggesting that our subjects habitually ate foods containing this carotenoid. As anticipated (Agarwal and Rao 1998; Paetau et al 1998; Rao and Agarwal 1998; Tyssandier et al 2004) LYs dramatically increased plasma lycopene, though it was not anticipated with our experimental design that supplementation with pure lycopene extract while under continued LYr would be associated with the observed significant increases in plasma $\beta$-carotene and $\alpha$-tocopherol. In contrast, plasma retinol was unaffected in response to LYr and LYs, perhaps due to its regulation by the liver (Ross and Zolfaghari 2004). At present, we have no explanation for the increases in plasma $\beta$-carotene and $\alpha$-tocopherol with LYs. Analysis of the diet logs did not show an increase in foods containing these compounds from the first to the second week of LYr, and we confirmed the supplements to be $>98 \%$ lycopene with no trace of $\alpha$-tocopherol or $\beta$-carotene. Furthermore the increase in these lipid-soluble antioxidants cannot be explained by a change in plasma total lipids, as cholesterol and triacylglycerol concentrations were unaffected by LYs.

The habitual plasma lipid-soluble antioxidants measured and the sex differences observed in the current study are well within the considerable variability established for and between healthy men and women in recent large-scale studies (Olmedilla et al 2001; Al Delaimy et al 2005). In response to LYs, plasma $\alpha$-tocopherol was increased similarly in our men and women but lycopene and $\beta$-carotene in women were only increased to a level matching their habitual concentrations whereas in men they were increased to a level exceeding their 
habitual concentrations. Interestingly, these data suggest that the women may have reached a biological limit of plasma lycopene by way of their habitual food intake whereas the men did not. Indeed, there is precedent for the concept of a biological limit of plasma lycopene in response to supplementation as evidenced by the fact that serum lycopene in humans has been shown to increase in a dose-independent manner (Agarwal and Rao 1998; Rao and Agarwal 1998). What might determine this biological limit of plasma carotenoid concentration and whether those determinants might be affected by sex remains to be elucidated.

Blood lipids, glucose, and insulin were unaffected by LYs in the present study, with the exception of an increase in glucose in the women. LYs did not affect any of the biomarkers of vascular oxidative stress or inflammation. In slightly older healthy men and women aged 25-40 years, 1-wk lycopenefree diet decreased serum lycopene $50 \%$ and increased blood lipid biomarkers of oxidative stress 25\% (Rao and Agarwal 1998), while supplementation with lycopene-containing foods doubled serum lycopene and reduced lipid biomarkers of oxidative stress $>20 \%$ (Agarwal and Rao 1998; Rao and Agarwal 1998). Similar to our findings, Briviba and colleagues (2004) recently showed that in healthy young men the plasma lipid oxidation metabolite malondialdehyde was unaffected by 2-wk tomato juice lycopene supplementation compared to a low-carotenoid diet. Plotnick and colleagues (2003) demonstrated that 4-wk phytonutrient supplementation increased plasma nitrate/nitrite by $\sim 45 \%$ in healthy middle-aged men and women; however in the current study we did not to find a difference in plasma nitrate/nitrite following LYs. Epidemiological data across the general population suggested that plasma lycopene and $\beta$-carotene were inversely related to sICAM-1 and CRP respectively (Herpen-Broekmans et al 2004), but another data set from a mixed group of healthy and diseased individuals found, consistent with our results following LYs, no correlation (Gianetti et al 2002). Taken altogether, the current study suggests that our young healthy subjects did not necessarily rely on lycopene intake or the plasma concentrations of the lipid-soluble antioxidants measured in order to control their level of plasma oxidative stress and inflammation. The above comparisons imply that the nature of the supplement (eg, pure extract vs antioxidant-containing foods), its duration of administration (eg, short-term, 1 to 2-wks vs longer-term, 4-wks), and likely most importantly the characteristics of the cohorts studied (eg, age, sex, physical activity level, dietary habits) may be responsible for discrepancies seen in the previous literature.

\section{Postprandial responses}

We set out to determine the effect of LYs and postprandial dyslipidemia on blood lipid-soluble antioxidants and biomarkers of vascular oxidative stress and inflammation in young healthy subjects. In the control conditions of LFm we found no change in plasma lipids or the oxidative stress marker malondialdehyde, and no effect of LYs on these responses. In response to the HFm plasma triacylglycerol increased $>85 \%$ and HDL cholesterol decreased $\sim 10 \%$. Plasma insulin was higher in females than males following the HFm but was still within values previously reported at the same time point in young healthy subjects (Raitakari et al 2000; Koutsari et al 2004; Blendea et al 2005). Higher insulin in females is consistent with studies showing a tendency for elevated insulin in young females after a HFm (Koutsari et al 2004) or glucose load (Flanagan et al 2006); conversely, some results find no postprandial gender differences (Ahmed et al 1976). Despite a marked postprandial dyslipidemia, malondialdehyde, sICAM-1, sVCAM-1, and CRP in the men remained unchanged from the fasting state both following LYr and with LYs, suggesting that the HFm did not impose a significant level of vascular oxidative stress or inflammation. Decreases in plasma lipid-soluble antioxidants and nitrate/nitrite observed after the HFm in our experiments, supported by some (Rao and Agarwal 1998; Blendea et al 2005) but not all (Brown et al 1989; Carroll and Schade 2003) reports, might signify that the meal-induced dyslipidemia perturbed the oxidative stress-nitric oxide system, although plasma $\alpha$-tocopherol and nitrate/nitrite were also decreased in men after the LFm where there was no dyslipidemia implying that a response common to both meals might have been responsible for the changes measured.

Our overall findings suggesting little to no change in markers of oxidative stress and/or inflammation with postprandial dyslipidemia in young healthy men and women were in part unexpected, especially following LYr when plasma lipid-soluble antioxidants were markedly reduced. Previous studies demonstrated that consuming a HFm increased blood biomarkers of oxidative stress and inflammation not only in healthy middle-aged subjects (Anderson et al 2001; Bae et al 2001; Nappo et al 2002; Ceriello et al 2002, 2004) but also in subjects of a very similar age to the men and women of our study (van Oostrom et al 2003; Tsai et al 2004). The HFm was associated with endothelial vasomotor dysfunction that could be reversed with antioxidants in both cohorts (Bae et al 2003; Esposito et al 2003; Plotnick et al 2003). Consistent with our findings other studies in young, healthy subjects reported no change in oxidative stress, inflammation 
(Schinkovitz et al 2001; Bae et al 2003; Tsai et al 2004) or endothelial vasomotor function (Tushuizen et al 2006) after a single HFm. Most noteworthy, a recent study by Tushuizen and colleagues (2006) found that endothelium-dependent flow-mediated dilation was no different up to 4-h after a 'fast food' HFm in healthy young subjects aged 20-35 yrs who were physically active training $\sim 6-\mathrm{h} /$ week, whereas consumption of a second HFm at 4-h lead to an increase in blood malondialdehyde, oxidized LDL, and cellular microparticles, and impairment of flow-mediated dilation. In this light, considering the cohort characteristics of the current study (aged 18-26 yrs, regularly physically active, with presumably healthy, balanced diets) it is possible that ingestion of not just one but a subsequent HFm (Tushuizen et al 2006) may have been needed to overcome our subjects' already robust vascular antioxidant buffering capacity and induce a pro-oxidative, pro-inflammatory response leading to transient vascular dysfunction, whereas ingestion of only one HFm may be all that is necessary in older and/or possibly more sedentary cohorts.

\section{Study limitations}

The current study provides new information regarding the effect of LYs and postprandial dyslipidemia on blood biochemical characteristics in humans; however, a number of potential limitations should be noted. First and foremost, from comparisons made in the Discussion of our findings to the available data in the literature, it appears that the young, physically active cohort examined in the present study may limit the ability to generalize how blood antioxidants and biomarkers of endothelial health respond to LYs and to a HFm. The possibility should also be considered that the measures of vascular oxidative stress and inflammation used in the cohort of the present study may not have been sensitive and/or specific enough to mark any changes occurring in these aspects of endothelial health, and that other more appropriate biomarkers might have revealed significant differences. In regard to the unanticipated increases in plasma $\beta$-carotene and $\alpha$-tocopherol concomitant with LYs, it might have been advantageous to have had our subjects record their habitual diets and provide weekly fasting blood samples 1-month prior to the commencement of the study, and provide blood samples daily throughout the study, as these data could have offered some insight into the plasma lipid-soluble antioxidant changes that occurred during LYr and LYs. Moreover, given that the purpose of our study was to determine only the short-term effects of lycopene manipulation, it now needs to be determined the extent to which young healthy subjects can control their levels of plasma lipid-soluble antioxidants, oxidative stress, and inflammation with a more prolonged LYr and/or LYs.

\section{Summary}

It may be concluded from this study that 1-wk of LYs markedly increased plasma lycopene as well as $\beta$-carotene and $\alpha$-tocopherol; however despite these changes to the plasma lipid-soluble antioxidant pool, biomarkers of vascular oxidative stress and inflammation were unaffected in young, active men and women both in the fasted state and following a HFm resulting in dyslipidemia. These data suggest that our subjects possessed an already robust antioxidant capacity capable of tightly maintaining vascular homeostasis and that LYs provided no additional benefit. Moreover, this study suggests that there are complex dynamics governing plasma lipid-soluble antioxidants in response to dietary supplementation and to ingesting both HFm and LFm, which merits future investigation as these dynamics might be involved in the control of vascular homeostasis.

\section{Acknowledgments}

The authors gratefully acknowledge and thank Myra Gonzales, Margaret Burnett and Thomas Irvine for their excellent technical assistance. This research was supported by the Natural Sciences and Engineering Research Council (RPG6473, RPG-2383) and the Heart and Stroke Foundation of Ontario (T5210, T5599). Steven G Denniss was supported by a NSERC Post-Graduate Fellowship and a University of Waterloo President's Graduate Scholarship. James Rush is supported by the Canada Research Chair program.

\section{References}

Agarwal S, Rao AV. 1998. Tomato lycopene and low density lipoprotein oxidation: a human dietary intervention study. Lipids, 33:981-4.

Ahmed M, Gannon MC, Nuttall FQ. 1976. Postprandial plasma glucose, insulin, glucagon and triglyceride responses to a standard diet in normal subjects. Diabetologia, 12:61-7.

Al Delaimy WK, Ferrari P, Slimani N, et al. 2005. Plasma carotenoids as biomarkers of intake of fruits and vegetables: individual-level correlations in the European Prospective Investigation into Cancer and Nutrition (EPIC). Eur J Clin Nutr, 59:1387-96.

Anderson RA, Evans ML, Ellis GR, et al. 2001. The relationships between post-prandial lipaemia, endothelial function and oxidative stress in healthy individuals and patients with type 2 diabetes. Atherosclerosis, $154: 475-83$

Bae JH, Bassenge E, Kim KB, et al. 2001. Postprandial hypertriglyceridemia impairs endothelial function by enhanced oxidant stress. Atherosclerosis, 155:517-23.

Bae JH, Schwemmer M, Lee IK, et al. 2003. Postprandial hypertriglyceridemiainduced endothelial dysfunction in healthy subjects is independent of lipid oxidation. Int J Cardiol, 87:259-67.

Blendea MC, Bard M, Sowers JR, et al. 2005. High-fat meal impairs vascular compliance in a subgroup of young healthy subjects. Metabolism, $54: 1337-44$. 
Bohm F, Tinkler JH, Truscott TG. 1995. Carotenoids protect against cell membrane damage by the nitrogen dioxide radical. Nat Med, 1:98-9.

Briviba K, Schnabele K, Rechkemmer G, et al. 2004. Supplementation of a diet low in carotenoids with tomato or carrot juice does not affect lipid peroxidation in plasma and feces of healthy men. $J$ Nutr, 134:1081-3.

Brown ED, Rose A, Craft N, et al. 1989. Concentrations of carotenoids, retinol, and tocopherol in plasma, in response to ingestion of a meal. Clin Chem, 35:310-2.

Carroll MF, Schade DS. 2003. Timing of antioxidant vitamin ingestion alters postprandial proatherogenic serum markers. Circulation, 108:24-31.

Ceriello A, Quagliaro L, Piconi L, et al. 2004. Effect of postprandial hypertriglyceridemia and hyperglycemia on circulating adhesion molecules and oxidative stress generation and the possible role of simvastatin treatment. Diabetes, 53:701-10.

Ceriello A, Taboga C, Tonutti L, et al. 2002. Evidence for an independent and cumulative effect of postprandial hypertriglyceridemia and hyperglycemia on endothelial dysfunction and oxidative stress generation: effects of short- and long-term simvastatin treatment. Circulation, 106:1211-8.

Clinton SK 1998. Lycopene: chemistry, biology, and implications for human health and disease. Nutr Rev, 56:35-51.

de Koning EJ, Rabelink TJ. 2002. Endothelial function in the post-prandial state. Atheroscler Suppl, 3:11-6.

Esposito K, Nappo F, Giugliano F, et al. 2003. Effect of dietary antioxidants on postprandial endothelial dysfunction induced by a high-fat meal in healthy subjects. Am J Clin Nutr, 77:139-43.

Flanagan DE, Holt RI, Owens PC, et al. 2006. Gender differences in the insulin-like growth factor axis response to a glucose load. Acta Physiol $(O x f), 187: 371-8$.

Gianetti J, Pedrinelli R, Petrucci R, et al. 2002. Inverse association between carotid intima-media thickness and the antioxidant lycopene in atherosclerosis. Am Heart J, 143:467-74.

Hansson GK 2001. Immune mechanisms in atherosclerosis. Arterioscler Thromb Vasc Biol, 21:1876-90.

Herpen-broekmans WMR, Klopping-Ketelaars IAA, Michiel BL, et al. 2004. Serum carotenoids and vitamins in relation to markers of endothelial. Eur J Epidemiol, 19:915-21.

Koenig W, Sund M, Frohlich M, et al. 1999. C-reactive protein, a sensitive marker of inflammation, predicts future risk of coronary heart disease in initially healthy middle-aged men: results from the MONICA (monitoring trends and determinants in cardiovascular disease) Augsburg Cohort Study, 1984 to 1992. Circulation, 99:237-42.

Kohlmeier L, Kark JD, Gomez-Garcia E, et al. 1997. Lycopene and myocardial infarction risk in the EURAMIC Study. Am J Epidemiol, 146:618-26.

Koutsari C, Zagana A, Tzoras I, et al. 2004. Gender influence on plasma triacylglycerol response to meals with different monounsaturated and saturated fatty acid content. Eur J Clin Nutr, 58:495-502.

Marchesi S, Lupattelli G, Schillaci G, et al. 2000. Impaired flow-mediated vasoactivity during post-prandial phase in young healthy men. Atherosclerosis, 153:397-402.

Martin KR, Wu D, Meydani M. 2000. The effect of carotenoids on the expression of cell surface adhesion molecules and binding of monocytes to human aortic endothelial cells. Atherosclerosis, 150:265-74

Nappo F, Esposito K, Cioffi M, et al. 2002. Postprandial endothelial activation in healthy subjects and in type 2 diabetic patients: role of fat and carbohydrate meals. J Am Coll Cardiol, 39:1145-50.

Olmedilla B, Granado F, Southon S, et al. 2001. Serum concentrations of carotenoids and vitamins $\mathrm{A}, \mathrm{E}$, and $\mathrm{C}$ in control subjects from five European countries. Br J Nutr, 85:227-38.

Paetau I, Khachik F, Brown ED, et al. 1998. Chronic ingestion of lycopene-rich tomato juice or lycopene supplements significantly increases plasma concentrations of lycopene and related tomato carotenoids in humans. Am J Clin Nutr, 68:1187-95.

Panasenko OM, Sharov VS, Briviba K, et al. 2000. Interaction of peroxynitrite with carotenoids in human low density lipoproteins. Arch Biochem Biophys, 373:302-5.
Pilz J, Meineke I, Gleiter C. 2000. Measurement of free and bound malondialdehyde in plasma by high-performance liquid chromatography as the 2,4-dinitrophenylhydrazine derivative. J Chromatogr Biomed Sci Appl, 742:315-25.

Plotnick GD, Corretti MC, Vogel RA, et al. 2003. Effect of supplemental phytonutrients on impairment of the flow-mediated brachial artery vasoactivity after a single high-fat meal. $J$ Am Coll Cardiol, 41:1744-9.

Raitakari OT, Lai N, Griffiths KA, et al. 2000. Enhanced peripheral vasodilation in humans after a fatty meal. $J$ Am Coll Cardiol, 36:417-22.

Rao AV, Agarwal S. 1998. Bioavailability and in vivo antioxidant properties of lycopene from tomato products and their possible role in the prevention of cancer. Nutr Cancer, 31:199-203.

Ridker PM, Hennekens CH, Roitman-Johnson B, et al. 1998. Plasma concentration of soluble intercellular adhesion molecule 1 and risks of future myocardial infarction in apparently healthy men. The Lancet, 351:88-92.

Rissanen T, Voutilainen S, Nyyssonen K, et al. 2002. Lycopene, atherosclerosis, and coronary heart disease. Exp Biol Med (Maywood), 227:900-7.

Rissanen TH, Voutilainen S, Nyyssonen K, et al. 2003. Serum lycopene concentrations and carotid atherosclerosis: the Kuopio Ischaemic Heart Disease Risk Factor Study. Am J Clin Nutr, 77:133-8.

Rodriguez MC, Rosenfeld J, Tarnopolsky MA. 2003. Plasma malondialdehyde increases transiently after ischemic forearm exercise. Med Sci Sports Exerc, 35:1859-65.

Ross AC, Zolfaghari R. 2004. Regulation of hepatic retinol metabolism: perspectives from studies on vitamin A status. $J$ Nutr, 134:269S-75S.

Schinkovitz A, Dittrich P, Wascher TC. 2001. Effects of a high-fat meal on resistance vessel reactivity and on indicators of oxidative stress in healthy volunteers. Clin Physiol, 21:404-10.

Sim AS, Salonikas C, Naidoo D, et al. 2003. Improved method for plasma malondialdehyde measurement by high-performance liquid chromatography using methyl malondialdehyde as an internal standard. J Chromatogr Biomed Sci Appl, 785:337-44.

Stahl W, Sies H. 1996. Lycopene: a biologically important carotenoid for humans? Arch Biochem Biophys, 336:1-9.

Stocker R, Keaney JF, Jr. 2004. Role of oxidative modifications in atherosclerosis. Physiological Reviews, 84:1381-478.

Su Q, Rowley KG, O’Dea K. 1999. Stability of individual carotenoids, retinol and tocopherols in human plasma during exposure to light and after extraction. J Chromatogr Biomed Sci Appl, 729:191-8.

Suarna C, Dean RT, May J, et al. 1995. Human atherosclerotic plaque contains both oxidized lipids and relatively large amounts of alpha-tocopherol and ascorbate. Arterioscler Thromb Vasc Biol, 15:1616-24.

Suganuma H, Inakuma T. 1999. Protective effect of dietary tomato against endothelial dysfunction in hypercholesterolemic mice. Biosci Biotechnol Biochem, 63:78-82.

Tsai WC, Li YH, Lin CC, et al. 2004. Effects of oxidative stress on endothelial function after a high-fat meal. Clin Sci, 106:315-9.

Tushuizen ME, Nieuwland R, Scheffer PG, et al. 2006. Two consecutive high-fat meals affect endothelial-dependent vasodilation, oxidative stress and cellular microparticles in healthy men. J Thromb Haemost, 4:1003-10

Tyssandier V, Feillet-Coudray C, Caris-Veyrat C, et al. 2004. Effect of tomato product consumption on the plasma status of antioxidant microconstituents and on the plasma total antioxidant capacity in healthy subjects. J Am Coll Nutr, 23:148-56.

van Oostrom AJ, Sijmonsma TP, Verseyden C, et al. 2003. Postprandial recruitment of neutrophils may contribute to endothelial dysfunction. J Lipid Res, 44:576-83.

Vogel RA, Corretti MC, Plotnick GD. 1997. Effect of a single high-fat meal on endothelial function in healthy subjects. Am J Cardiol, 79:350-4.

Widlansky ME, Gokce N, Keaney JF, Jr. et al. 2003. The clinical implications of endothelial dysfunction. J Am Coll Cardiol, 42:1149-60.

Williams MJ, Sutherland WH, McCormick MP, et al. 1999. Impaired endothelial function following a meal rich in used cooking fat. $J \mathrm{Am}$ Coll Cardiol, 33:1050-5. 